\title{
Polski Współczynnik Wpływu a kultury cytowań w humanistyce
}

\begin{abstract}
STRESZCZENIE. W artykule omawiamy wzór na nowy polski wskaźnik bibliometryczny, tj. Polski Współczynnik Wpływu, z perspektywy nauk humanistycznych. Badaniom poddaliśmy dwa prestiżowe polskie czasopisma humanistyczne (Pamiętnik Literacki i Diametros - An Online Journal of Philosophy), aby sprawdzić poprawność założeń przyjętych dla Polskiego Współczynnika Wpływu. Przeanalizowaliśmy wszystkie artykuły opublikowane w latach 2004-2014 (odpowiednio: $N=850$, $N=555$ ) i wszystkie prace w nich zacytowane (odpowiednio: $N=21805, N=8298$ ). W interpretacji wyników przyjęliśmy założenie o odmiennej kulturze cytowań w różnych grupach nauk. Wyniki pokazują, że wzór na Polski Współczynnik Wpływu nie bierze pod uwagę najczęściej cytowanych źródeł w humanistyce, tj. książek i rozdziałów. Poza tym wiele cytowań nie zostanie uwzględnionych przy wyliczaniu Polskiego Współczynnika Wpływu ze względu na ich wiek, ponieważ będą brane pod uwagę prace co najwyżej pięcioletnie. Zbadaliśmy wiek cytowanych tekstów i pokazaliśmy, że większość cytowań jest starsza niż 5 lat (odpowiednio: 84,2\% i 73,2\%). Nasza analiza pokazuje, że Polski Współczynnik Wpływu nie jest odpowiednim narzędziem do bibliometrycznej oceny czasopism humanistycznych w Polsce. Artykuł kończy dyskusja nad możliwościami ulepszenia tego nowego wskaźnika bibliometrycznego.
\end{abstract}

SŁOWA KLUCZOWE: Polski Współczynnik Wpływu, kultura cytowań, humanistyka, bibliometria, wykaz czasopism punktowanych

\section{Wprowadzenie}

Polski Współczynnik Wpływu (PWW) ma być wskaźnikiem bibliometrycznym służącym do ewaluacji polskich czasopism naukowych, która jest przeprowadzana przez Ministerstwo Nauki i Szkolnictwa Wyższego na potrzeby kompleksowej ewaluacji jednostek naukowych. Założenia oraz wzór na PWW zostały zaprezentowane w komunikacie Ministra Nauki i Szkolnictwa Wyższego z dnia 29 maja 
2013 r. w sprawie kryteriów i trybu oceny czasopism naukowych (zwanym dalej Komunikatem MNiSW z 2013 r.). Jerzy Wilkin (2013) pisał, że PWW będzie wykorzystany w ocenie czasopism już w 2013 r. Emanuel Kulczycki (2014) podkreślał, że zaprezentowana konstrukcja PWW - opierająca się na danych wprowadzonych do bazy POL-index, w której nie uwzględnia się cytowań polskich artykułów w monografiach i pracach zwartych oraz uwzględnia się autocytowania z czasopism (bez względu na ich odsetek) - sprawi, że uzyskany wynik PWW będzie trudny do zinterpretowania i da zniekształcony obraz praktyk publikacyjnych polskich badaczy.

Ocena zasadności budowy i założeń PWW nie została do tej pory zbadana. Taka analiza nie jest możliwa bez wykorzystania danych bibliograficznych z polskich czasopism naukowych. Jednocześnie to właśnie brak tych danych był najważniejszym powodem zaproponowania PWW - nie można obliczyć wskaźnika wpływu opartego na cytowaniach, jeśli czasopismo nie jest indeksowane w bazie bibliograficzno-bibliometrycznej, np. Web of Science ${ }^{\mathrm{TM}}$ Core Collection (WoS) czy SCOPUS. PWW ma być stosowany do ewaluacji krajowych czasopism naukowych, które w większości publikują artykuły w języku polskim - to natomiast może być jedna z przyczyn nieindeksowania tych czasopism w przywołanych bazach. Oznacza to, że PWW ma być odpowiedzią na problemy związane z ewaluacją czasopism polskich oraz lokalną specyfiką ocenianego przedmiotu. Jednakże o tej specyfice nie decyduje jedynie lokalność, rozumiana jako publikowanie głównie w języku narodowym, ale również kultura cytowań, która także powinna być uwzględniona w założeniach i wzorze na PWW.

Kultura cytowań to termin opisujący strukturę i reguły cytowania, tj. odnoszenia się do innych opublikowanych prac, typowa dla danego obszaru nauki, a czasem nawet czasopism (Wouters 1999). Kultura cytowań oznacza zatem zbiór cech, którymi można opisać najczęściej występujące sposoby cytowań na danym analizowanym poziomie, $\mathrm{np}$. w humanistyce cytuje się przede wszystkim prace jednoautorskie (Hellqvist 2009: 314). Kultura cytowań określa najczęściej: 1) jaki kanał komunikacji odgrywa najważniejszą rolę (Hammarfelt 2012; Konieczna 2002), np. czy są to książki, czy czasopisma; 2) jakim wiekiem charakteryzują się cytowane prace, tj. czy cytuje się głównie prace nowe, czy też starsze (Barnett, Fink i Debus 1989); 3) czy cytuje się prace, aby przywołać fakty, czy raczej dookreślić kontekst (Todd i Ladle 2008); 4) czy używa się przypisów dolnych, czy odwołań w tekście do prac innych autorów (Hellqvist 2009); 5) z jakich krajów oraz publikujących w jakim języku autorów najczęściej się cytuje (Winclawska 1996). Oznacza to, że różnice w kulturze cytowań wyznaczają sposób interpretacji danych bibliometrycznych. Dlatego tak istotne jest uwzględnienie specyfiki obszarów nauki w założeniach PWW.

Celem niniejszego artykułu jest sprawdzenie założeń PWW z punktu widzenia kultury cytowań w polskiej humanistyce. W ten sposób odpowiadamy na pytanie, 
czy tak skonstruowany PWW jest użytecznym narzędziem do bibliometrycznej oceny krajowych czasopism naukowych. Nie dokonujemy symulacji wyników PWW, ta bowiem nie jest możliwa bez oparcia się na pełnym zbiorze danych zgromadzonych w bazie POL-index. W związku z tym stawiamy następującą hipotezę badawczą: przedstawiona konstrukcja założeń PWW jest niezasadna z perspektywy bibliometrycznej oceny czasopism z grupy nauk humanistycznych. Wynika to z wykorzystania wyłącznie tych danych, które pochodzą z czasopism, i pominięcia książek, które są dominującym kanałem komunikacji naukowej w humanistyce. W ten sposób PWW, nie uwzględniając kultury cytowań w humanistyce, staje się nieadekwatnym narzędziem do ewaluacji krajowych czasopism naukowych. Brak różnicowania PWW na dyscypliny naukowe jest również niezasadny z uwagi na znaczące różnice pomiędzy wiekiem cytowań w humanistyce a innych grupach nauk.

Przedmiotem naszych analiz są założenia i wzór na PWW oraz cytowania z dwóch polskich czasopism humanistycznych, tj. Pamiętnika Literackiego (PL) i Diametros - An Online Journal of Philosophy (DOJP), z lat 2004-2014.

Sformułowaliśmy cztery pytania badawcze, które stały się podstawą naszych analiz:

1. Jaki jest rozkład cytowań ze względu na typ publikacji? Czy publikacje z czasopism są cytowane istotnie częściej niż książki i rozdziały?

2. Czy istnieje tendencja do zwiększania się w czasie liczby cytowań publikacji $\mathrm{z}$ czasopism?

3. Jaki jest rozkład cytowań ze względu na ich wiek? Jaki jest odsetek cytowań, których wiek wynosi od 1 do 5 lat (cytowania te spełniają kryteria określone we wstępnej definicji PWW)?

4. Jaki jest odsetek autocytowań czasopisma?

Przeprowadzone przez nas analizy pokazują, że wśród cytowań znajdują się cytowania polskich czasopism naukowych. Istnieje zatem możliwość wyliczenia PWW dla polskich czasopism humanistycznych. Jednak tak obliczony PWW nie będzie ukazywać faktycznego wpływu (mierzonego wskaźnikami bibliometrycznymi) tych czasopism, gdyż baza POL-index stanowiąca podstawę obliczeń nie uwzględnia dominujących w humanistyce typów publikacji: książek i rozdziałów. Znaczna część cytowań w humanistyce nie zostanie zaliczona do danych uwzględnianych w PWW ze względu na ich wiek. W ten sposób założenia PWW ignorują kulturę cytowań w humanistyce, która jest zdecydowanie odmienna od kultury cytowań w „twardych" naukach, gdzie dominującym typem są artykuły w czasopismach, a znacząca liczba cytowań ma krótki wiek.

Struktura niniejszego tekstu jest następująca: w części pierwszej prezentujemy podstawowe założenia oraz wzór na Polski Współczynnik Wpływu. W części drugiej omawiamy kryteria doboru analizowanych czasopism oraz sposób zbierania i analizy danych. W części trzeciej prezentujemy wyniki analizy cytowań w humanistyce 
na podstawie zebranych danych oraz zaprezentowanego w komunikacie MNiSW z 2013 r. wzoru na PWW. W ostatniej części przedstawiamy dyskusję oraz uwagi końcowe odnoszące się do założeń PWW.

\section{Założenia i budowa Polskiego Współczynnika Wpływu}

W komunikacie MNiSW z 2013 r. informowano, że PWW zostanie włączony do oceny czasopism z części B „Wykazu czasopism punktowanych” w 2014 r. Jednakże kolejna ocena nie odbyła się w 2014, ale w 2015 r. Wówczas również nie wykorzystano PWW. Ponadto zrezygnowano z publikacji dotychczasowego wzoru na PWW oraz nie zaproponowano nowego w komunikacie MNiSW z dnia 2 czerwca 2015 r. w sprawie kryteriów i trybu oceny czasopism naukowych. Zastosowano jednakże mechanizm („gratyfikację punktową”) zachęcający redakcje do wprowadzenia danych do bazy POL-index będącej podstawą wyliczania PWW (Kulczycki, Rozkosz i Drabek 2016).

W komunikacie MNiSW z 2013 r. określono, że dane pozwalające wyliczyć PWW mają obejmować:

a) pełne rekordy bibliograficzne wszystkich artykułów opublikowanych w czasopiśmie naukowym w okresie dwóch lat poprzedzających rok wypełnienia ankiety zawierające następujące informacje:

- tytuł artykułu,

- tytuł artykułu w innych językach,

- typ artykułu,

- tom/numer,

- rok,

- zakres stron,

- język artykułu,

- imiona i nazwiska autorów,

- wykaz cytowanej literatury (bibliografia załącznikowa lub jej opracowanie na podstawie przypisów dolnych lub końcowych);

b) skrócone rekordy bibliograficzne wszystkich artykułów opublikowanych w czasopiśmie naukowym, od $2007 \mathrm{r}$., zawierające:

- tytuł artykułu,

- tytuł artykułu w innych językach,

- typ artykułu,

- tom/numer,

- rok,

- zakres stron,

- język artykułu,

- imiona i nazwiska autorów. 
Dodatkowo, według komunikatu MNiSW z 2013 r., można było podać informacje fakultatywne ${ }^{1}$ : w przypadku rekordów pełnych i skróconych - afiliację autorów artykułu; w przypadku rekordów skróconych - wykaz cytowanej literatury. Wzór na PWW określono następująco:

$$
P W W=\frac{C^{s}(s-5, s-1)}{N^{(s-5, s-1)}}+\frac{C^{s-1}(s-6, s-2)}{N^{(s-6, s-2)}}
$$

gdzie:

$S \quad$ rok poprzedzający rok wypełniania ankiety czasopisma

$C_{(s-5, s-1)}^{s} \quad$ liczba cytowań, jakie uzyskały w roku s wszystkie artykuły naukowe opublikowane w czasopiśmie w latach od s-5 do s-1

$N^{(s-5, s-1)} \quad$ liczba cytowalnych tekstów opublikowanych w czasopiśmie w latach od $\mathrm{s}-5$ do $\mathrm{s}-1$

$C_{(s-6, s-2)}^{s-1}$ liczba cytowań, jakie uzyskały w roku s-1 wszystkie artykuły naukowe opublikowane w czasopiśmie w latach od s-6 do s-2

$N^{(s-6, s-2)} \quad$ liczba cytowalnych tekstów opublikowanych w czasopiśmie w latach od s-6 do s-2

Kiedy we wzorze mowa jest o tekstach cytowalnych, chodzi o - zgodnie z zasadami budowy „Wykazu czasopism punktowanych” - artykuły naukowe, a nie np. recenzje czy nekrologi. Jednakże o ile w mianowniku uwzględniane są wyłącznie teksty cytowalne, to do licznika włączane są również cytowania tekstów niecytowalnych.

Warto zauważyć, że zaproponowany wzór na PWW przypomina znany, lecz zmodyfikowany wskaźnik bibiometryczny, tj. pięcioletni Impact Factor (5-year IF), który jest stosowany przez Thomson Reuters (Jacsó 2009) od 2009 r. i który jest obliczany na podstawie danych zgromadzonych w WoS.

Wzór na pięcioletni Impact Factor przedstawiony za pomocą notacji stosowanej dla PWW wygląda następująco:

$$
5 \text {-year } I F=\frac{C^{s}(s-5, s-1)}{N^{(s-5, s-1)}}
$$

W tym wzorze również występuje podział na teksty cytowalne (uwzględniane w mianowniku) i teksty niecytowalne. Zatem wskaźnik PWW można zinterpreto-

${ }^{1}$ Komunikat MNiSW z 2015 r. dał możliwość wskazywania: roli autora w tworzeniu artykułu, języków abstraktów, dziedzin i dyscyplin dotyczących artykułu, słów kluczowych oraz DOI. 
wać jako sumę pięcioletnich Impact Factorów obliczanych dla dwóch kolejnych lat na podstawie odrębnego zbioru danych (POL-index), pod warunkiem, że w latach tych ukazała się taka sama liczba tekstów cytowalnych.

Przy określaniu liczby cytowań na potrzeby wyliczenia PWW, aby uniknąć dwukrotnego zaliczania tych samych danych, uwzględnia się jedynie cytowania pochodzące z czasopism naukowych nieindeksowanych w bazach uwzględnianych przy wyliczaniu wskaźnika Predicted Impact Factor (PIF), tj. bazach Science Citation Index Expanded, Social Sciences Citation Index oraz Arts \& Humanities Citation Index. Wskaźnik PIF jest dotychczasowym wskaźnikiem wykorzystywanym przede wszystkim do oceny krajowych czasopism naukowych, lecz właśnie ze względu na jego nieadekwatność do oceny czasopism lokalnych zaproponowano PWW.

W związku z takimi zasadami budowy wskaźnika można wskazać pięć istotnych obszarów ograniczających zasadność i użyteczność PWW.

Po pierwsze, bazowanie jedynie na cytowaniach zawartych w krajowych czasopismach, które chcą być poddane ewaluacji i znaleźć się w „Wykazie czasopism punktowanych”. Zawężenie zbioru danych tylko do czasopism, które chcą być ewaluowane, jest istotnym ograniczeniem, którego uzasadnienia nie można wskazać na gruncie analiz bibliometrycznych, a jedynie w ramach przyjętej i stosowanej polityki naukowej. Nie wiadomo też, czy redakcje będą chciały kontynuować w kolejnych latach wpisywanie danych do POL-indexu bez pewności, że otrzymają za to gratyfikację punktową w ocenie. W tej sytuacji trudno prognozować, w jakim kierunku będzie się rozwijała baza.

Po drugie, zawężenie zbieranych danych jedynie do czasopism, czyli pominięcie innych potencjalnych źródeł cytowań, takich jak książki czy rozdziały. Jest to oczywiście rozwiązanie analogiczne do tego stosowanego przez firmę Thomson Reuters wyliczającą wskaźnik Impact Factor (IF). Jednakże baza ta indeksuje o wiele więcej czasopism niż baza POL-index. Dodatkowo nie jest wyliczany wskaźnik dla czasopism z zakresu humanistyki, co ma swoje źródło m.in. w odmiennym dla tej grupy nauk dominującym kanale komunikacji naukowej.

Po trzecie, założenie dotyczące wieku cytowań - we wzorze na PWW określono sześcioletnie „okienko cytowań”, czyli przy wyliczaniu wskaźnika bierze się pod uwagę cytowania, których wiek wynosi od 1 do 5 lat $^{2}$. Jest to okres dłuższy niż ten przyjęty dla wskaźnika IF, jednak PWW ma służyć również do oceny czasopism humanistycznych, którym - właśnie ze względu na odmienną kulturę cytowań - nie wylicza się wskaźnika IF.

${ }^{2}$ PWW obliczany w 2016 r. dla przykładowego czasopisma w oparciu o przedstawiony wzór będzie obejmować cytowania artykułów z roczników 2009-2014, a ściśle cytowania, jakie uzyskały w 2015 r. artykuły z roczników 2010-2014, oraz cytowania, jakie uzyskały w 2014 r. artykuły z roczników 2009-2013. Podstawą obliczeń są więc cytowania, które uzyskały artykuły z sześciu roczników, przy czym liczy się odrębnie cytowania uzyskane przez czasopismo w dwóch kolejnych latach, co sprawia, że wiek uwzględnianych cytowań wynosi od 1 do 5 lat, a nie od 1 do 6 lat. 
Po czwarte, uwzględnianie we wzorze na PWW autocytowań na poziomie czasopism (cytowanie odnosi się do artykułu opublikowanego w danym czasopiśmie) bez względu na ich odsetek. Może to skutkować niesłusznym docenieniem czasopism posiadających wysoki wskaźnik autocytowań przy braku lub niskiej liczbie cytowań uzyskanych od innych czasopism.

Po piąte, jakość zbieranych danych - dane są wprowadzane przez przedstawicieli redakcji i nie są weryfikowane czy poprawiane przez operatorów bazy. Ponadto polskie czasopisma nie stosują powszechnie identyfikatora DOI w opisach bibliograficznych, co pozwoliłoby na skuteczniejsze tworzenie poprawnych powiązań między rekordami w bazie POL-index. Taki sposób zbierania danych budzi istotne zastrzeżenia ze względu na możliwość zidentyfikowania i połączenia ze sobą publikacji cytujących z cytowanymi. Dodatkowo bardzo różne style cytowań stosowane w polskich czasopismach mogą utrudnić parsowanie danych i tym samym wpłynąć na wielkość PWW.

Zgodnie z celem postawionym w niniejszym artykule przeanalizujemy, czy tak skonstruowany wskaźnik odpowiada na potrzeby, które ma realizować, tj. dostarczyć narzędzie bibliometrycznej oceny krajowych czasopism. Skupimy się na obszarze nauk humanistycznych, gdyż cechują się one odmienną kulturą cytowań od nauk „twardych” (Hammarfelt 2012; Hellqvist 2009; Kolasa 2013), w związku z czym założenia wskaźników bibliometrycznych powinny być dostosowane do tej specyfiki.

\section{Materiały i metody}

Do naszych badań wybraliśmy dwa humanistyczne czasopisma naukowe, tj. Pamiętnik Literacki (PL) i Diametros - An Online Journal of Philosophy (DOJP) . Są to czasopisma reprezentatywne dla swoich dyscyplin: literaturoznawstwa i filozofii. Analizie poddaliśmy dane bibliograficzne z lat 2004-2014: po 11 kompletnych roczników czasopism. W odniesieniu do PL stanowiło to 44 zeszyty, natomiast w przypadku DOJP - 42 zeszyty.

\subsection{Materiały}

Przyjęliśmy następujące jakościowe kryteria doboru próby, czyli czasopism PL i DOJP. Wybierając czasopisma, uznaliśmy, że powinny to być:

- czasopisma o jasno określonym profilu tematycznym, wyraźnie związane z wybraną dyscypliną humanistyczną. PL jest czasopismem literaturoznawczym, natomiast DOJP filozoficznym;

- czasopisma uznane za prestiżowe na podstawie eksperckiej oceny autorów będących pracownikami nauki i reprezentującymi dyscypliny: filozofię i literaturo- 
znawstwo. Przy wyłanianiu czasopism nie zostały uwzględnione te, z którymi autorzy niniejszego artykułu współpracują i/lub w których posiadają publikacje;

- czasopisma naukowe, w których publikowane są przede wszystkim teksty poddane naukowej recenzji;

- czasopisma istniejące od co najmniej 10 lat, a zatem niedebiutujące na rynku naukowym, lecz posiadające już ustabilizowaną pozycję wydawniczą. PL ma 114 lat, ukazuje się niemal nieprzerwanie od 1902 r. (poza przerwą wojenną, 1939-1945). DOJP ma 12 lat, ukazuje się od 2004 r.;

- czasopisma indeksowane w uznanych bazach o zasięgu międzynarodowym, co stanowi potwierdzenie wysokich standardów wydawniczych charakteryzujących te czasopisma. PL jest indeksowane w WoS (we wchodzącej w skład WoS bazie Arts and Humanities Citation Index), natomiast DOJP w bazie SCOPUS;

- czasopisma wydawane przez ważne ośrodki naukowe. PL jest wydawany przez Wydawnictwo Instytutu Badań Literackich Polskiej Akademii Nauk, natomiast DOJP przez Instytut Filozofii Uniwersytetu Jagiellońskiego;

- czasopisma ukazujące się regularnie (brak przerw), z wysoką i niezmienną częstotliwością. PL i DOJP są kwartalnikami;

- czasopisma, których pełne zeszyty w wyznaczonym do analizy okresie dostępne są w wersji cyfrowej. Zawartość PL udostępniona jest w bazach: BazHum i Central and Eastern European Online Library (CEEOL). Natomiast DOJP udostępnia pełne zeszyty na własnej stronie internetowej.

\subsection{Sposób zbierania danych}

Zgromadziliśmy dane bibliograficzne o tekstach opublikowanych w PL i DOJP oraz tekstach przez nich cytowanych, czyli cytowaniach ${ }^{3}$.

Źródłem danych dla PL były: 1) dla danych z lat 2004-2009: baza Arton Polska Literatura Humanistyczna4; 2) dla lat 2010-2014 zeszyty czasopisma w wersji cyfrowej dostępne w bazie BazHum oraz Central and Eastern European Online Library (CEEOL). Źródłem danych dla DOJP były zeszyty czasopisma w wersji cyfrowej.

${ }^{3} \mathrm{~W}$ niniejszym artykule terminu „cytowania” używamy przede wszystkim dla tekstów cytowanych w analizowanych czasopismach, tj. odsyłaczy bibliograficznych. Odpowiednikiem tego terminu w języku angielskim jest references. Cytowania w języku angielskim określa się również jako citations, jednakże tak rozumiane cytowania (inaczej cytacje) odnoszą się do prac cytujących czasopisma będące przedmiotem analizy.

4 Baza Arton była inicjatywą Uniwersytetu Śląskiego i w założeniu miała stać się polskim indeksem cytowań literatury humanistycznej. Baza w latach 1999-2010 indeksowała 24 tytuły polskich czasopism z językoznawstwa, literaturoznawstwa i etnologii, zbierając dane bibliograficzne opublikowanych tam tekstów oraz opisy cytowanych prac (Drabek 2009). Od 2011 r. projekt ten, ze względu na brak dofinansowania, nie jest kontynuowany. 
Cytowania podzieliliśmy na sześć typów (podstawą przyporządkowania do odpowiedniego typu była analiza opisu bibliograficznego):

- artykuł w czasopiśmie: tekst opublikowany w czasopiśmie naukowym lub nienaukowym (np. czasopiśmie fachowym, tygodniku, dzienniku);

- książka: zarówno monografie naukowe, jak i książki niebędące monografiami naukowymi (np. dzieła literackie), książki autorskie i pod redakcją;

- rozdział: wyodrębniony fragment, zarówno rozdziały w monografiach naukowych, jak i rozdziały w książkach niebędących monografiami naukowymi;

- czasopismo: całe czasopismo lub zeszyt czasopisma;

- archiwalia: np. rękopisy;

- dokument elektroniczny: np. strona internetowa, korespondencja elektroniczna;

- inne.

Wszystkie obliczenia wykonaliśmy za pomocą pakietu IBM SPSS Statistics 23.

\section{Analiza kultury cytowań}

Analizę wykonaliśmy na podstawie danych bibliograficznych z PL i DOJP odnoszące się do: opublikowanych tekstów (odpowiednio: $N=850, N=555$ ) oraz cytowań (odpowiednio: $N=21805, N=8298$ ). Przebadaliśmy te aspekty kultury cytowań, które mają znaczenie dla dyskusji nad założeniami dla PWW. Jednak nie uwzględniliśmy w analizie cech cytowań nieistotnych z punktu widzenia PWW (np. język, autocytowania autorów).

\subsection{Typ publikacji}

Sprawdziliśmy, jakie typy publikacji były cytowane przez autorów tekstów w analizowanych czasopismach. Chcieliśmy tym samym ustalić, czy artykuły w czasopismach stanowią istotny kanał komunikacji naukowej w humanistyce, tj. czy są one częściej cytowane od książek. Przyjęliśmy, że przewaga książek i rozdziałów wśród cytowań będzie istotnym argumentem za rozszerzeniem indeksu cytowań (POL-indexu) o dane na temat monografii naukowych i ich części.

Wykres 1 pokazuje rozkład cytowań w PL i DOJP ze względu na typ publikacji. Najczęściej cytowanymi typami publikacji okazały się książki (odpowiednio: 49,6\% i 46\%). Dodaliśmy do siebie cytowania książek i rozdziałów, aby porównać je z cytowaniami artykułów. W PL odsetek cytowań artykułów wynosił 21,3\%, natomiast książek i rozdziałów - 76,2\%. Podobny wynik uzyskaliśmy w przypadku czasopisma DOJP, w którym odsetek artykułów wynosił 27,3\%, a książek i rozdziałów 67,5\%. W obu czasopismach książki i rozdziały były cytowane istotnie częściej (dwa lub trzy razy częściej) niż artykuły. Przewaga cytowań książek i rozdziałów potwier- 
Wykres 1. Liczba cytowań w czasopismach PL i DOJP

odnoszących się do poszczególnych typów publikacji

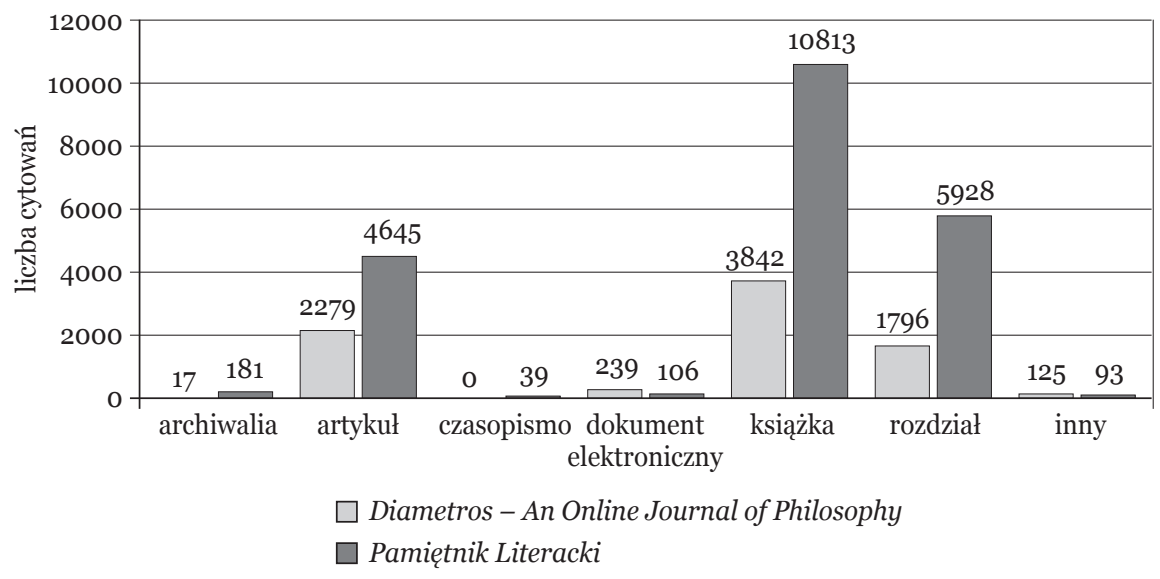

Źródło: opracowanie własne.

dza tezę o dominacji tego typu publikacji w komunikacji naukowej w humanistyce, co prowadzi do wnosku, że konieczne jest uwzględnienie książek, tj. monografii naukowych i rozdziałów w monografiach naukowych, w bazach bibliograficzno-bibliometrycznych, co pozwoli na większe pokrycie w tych bazach publikacji humanistycznych.

Zbadaliśmy, czy praktyki w zakresie cytowań ulegają zmianie, a zatem czy rośnie w czasie odsetek cytowań dla artykułów w czasopismach i jednocześnie maleje odsetek cytowań dla książek i rozdziałów.

Rysunki 2 i 3 pokazują, jak zmieniał się odsetek cytowań dla obu wyróżnionych typów publikacji w latach 2004-2014. Nie odnotowaliśmy w żadnym czasopiśmie tendencji wzrostowej dla odsetka cytowań w artykułach i zmniejszania się w czasie odsetka cytowań dla książek i rozdziałów.

Jednocześnie zauważyliśmy różnice pomiędzy PL i DOJP w zakresie cytowanych w poszczególnych latach typów publikacji. W PL odsetek cytowań książek i rozdziałów był wysoki w całym okresie (2004-2014), znacząco wyższy od odsetka cytowań artykułów, i kształtował się w przedziale 42,3-64,3\%. W DOJP odsetek cytowań książek i rozdziałów również był wyższy niż odsetek cytowań artykułów, jednak różnica pomiędzy tymi wartościami ulegała znaczącym zmianom, wahając się od 9,2\% do 64,3\%. Mniejszą różnicę pomiędzy odsetkiem cytowań artykułów a odsetkiem cytowań książek i rozdziałów wyjaśnia obecność w danym roku dużej liczby artykułów z zakresu bioetyki, np. w 2009 r. ukazał się zeszyt tematyczny Szpitalne komisje etyczne, w 2010 r. zeszyt Prawo do życia, a w 2012 r. zeszyt Bioetyka i genetyka. Lata, w których różnica pomiędzy odsetkami analizowanych 
Wykres 2. Odsetek cytowań artykułów oraz książek i rozdziałów w czasopiśmie PL

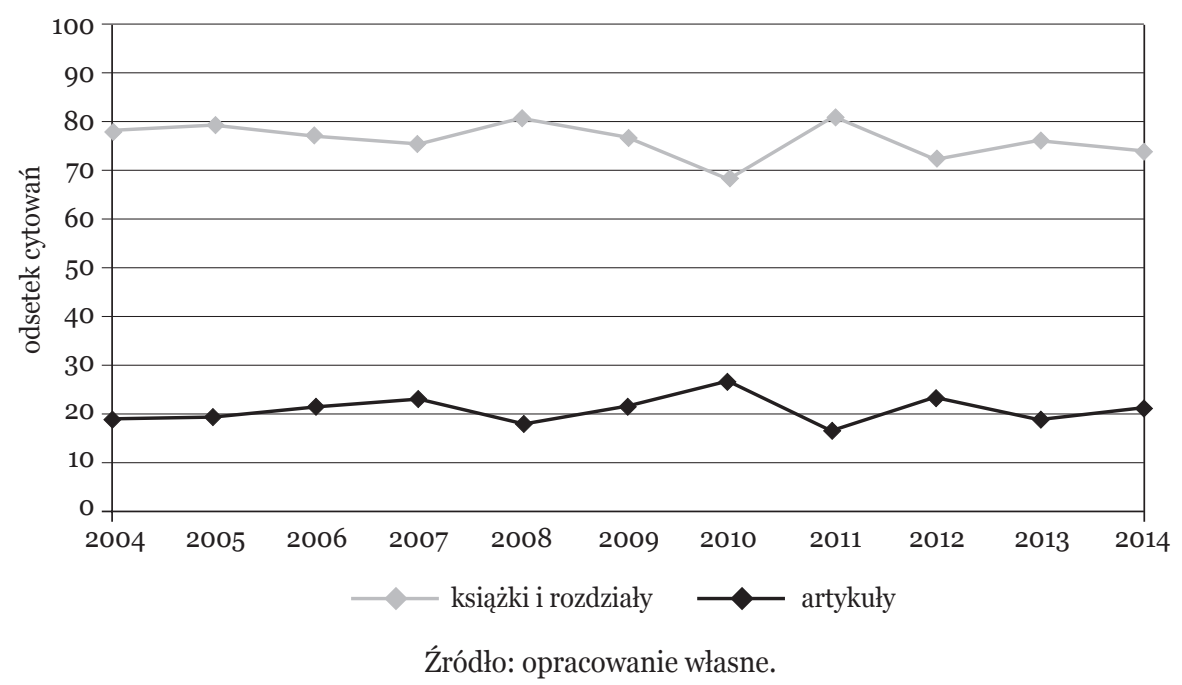

Wykres 3. Odsetek cytowań artykułów oraz książek i rozdziałów w czasopiśmie DOJP

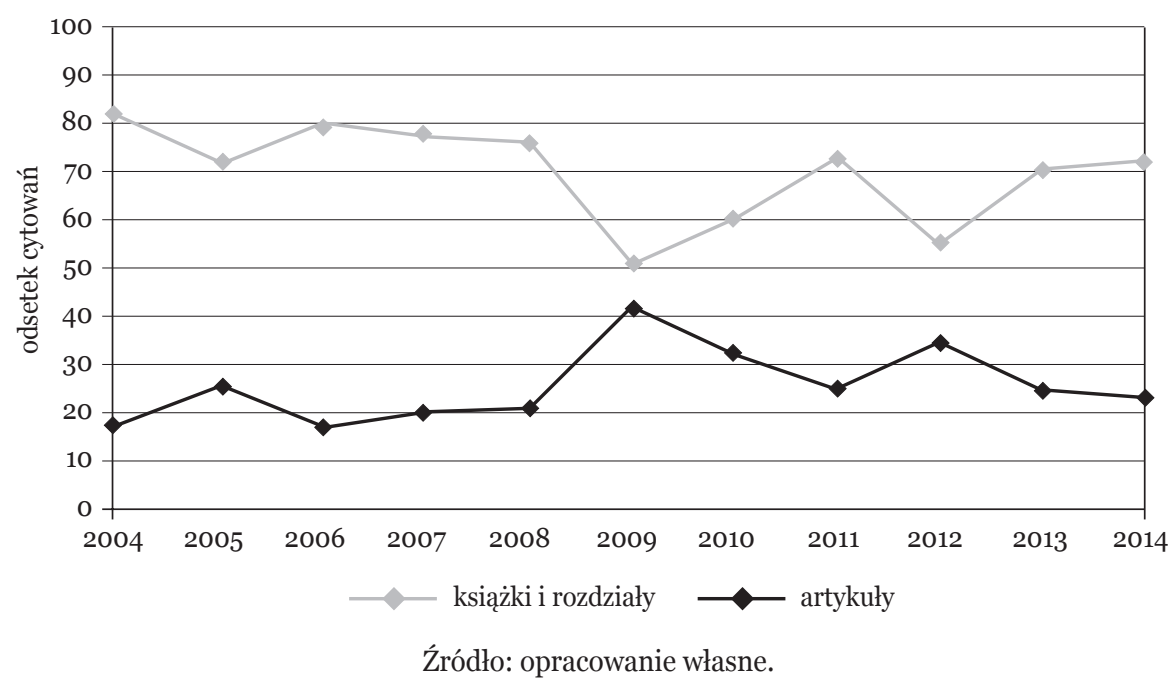

typów publikacji była największa, charakteryzuje brak lub niewielka liczba artykutów interdyscyplinarnych, tj. łączących problematykę filozoficzną z medyczną.

Przedstawione wyniki odpowiadają na dwa pytanie badawcze: 1. Jaki jest rozkład cytowań ze względu na typ publikacji? Czy publikacje z czasopism są cytowane 
istotnie częściej niż książki i rozdziały? 2. Czy istnieje tendencja zwiększania się w czasie liczby cytowań publikacji z czasopism?

\subsection{Wiek cytowań}

Ustaliliśmy wiek cytowań określający różnicę między rokiem publikacji tekstu cytującego a rokiem publikacji tekstu cytowanego (cytowania). Sprawdziliśmy średni wiek $(M)$, odchylenie standardowe $(S D)$ i ksztalt rozkładu wieku cytowań w obu czasopismach. Rozkład wieku cytowań był prawoskośny zarówno w PL ( $M=33,95$; $S D=47,166$; skośność = 4,337; błąd standardowy skośności = 0,017), jak i w DOJP $(M=19,33 ; S D=27,3$; skośność = 4,472; błąd standardowy skośności = 0,027). Znaczącą większość cytowań stanowily cytowania o długim wieku. Cytowania te tworzyły na histogramie wyników tzw. długi ogon.

Aby określić, jak duży odsetek cytowań wykracza poza założenia PWW, podzieliliśmy je na trzy grupy, tj. cytowania w wieku: 1) o lat (rok publikacji pracy cytowanej jest taki sam jak pracy cytującej), 2) od 1 do 5 lat, 3) powyżej 5 lat. Założenia dla wieku spełniały cytowania, których wiek wynosił od 1 do 5 lat, co wynika ze wzoru na PWW. Rysunek 4 prezentuje odsetek cytowań z trzech grup, odrębnie dla PL i DOJP. Założenia dla wieku spełniało zaledwie 15,3\% cytowań z PL i 24,1\% cytowań dla DOJP.

Do interpretacji wyniku wykorzystaliśmy indeks Price'a (Price’s Index) określający, jaki odsetek cytowań odnotowanych w zbiorze danych (np. zbiorze czasopism naukowych) stanowily cytowania tekstów opublikowanych w danym czasopiśmie, dla którego obliczany jest indeks, w okresie minionych 5 lat. Price (1970) poka-

Wykres 4. Odsetek cytowań w czasopismach PL i DOJP, których wiek wynosi o, od 1 do 5 lat i powyżej 5 lat

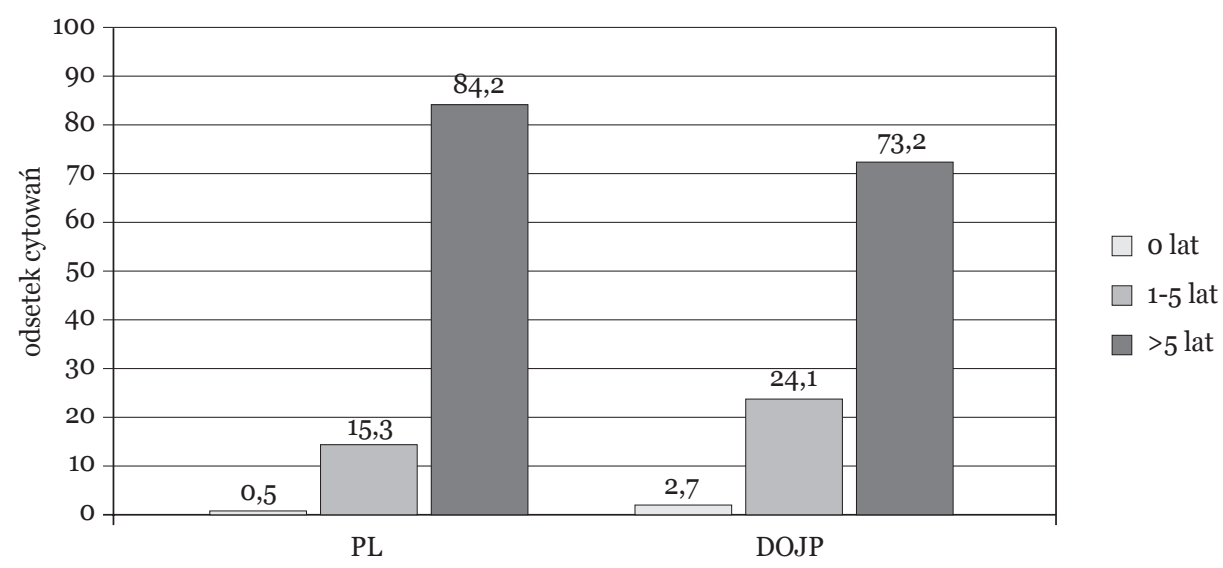

Źródło: opracowanie własne. 
zał przydatność tego wskaźnika w opisywaniu różnic pomiędzy kulturami cytowań w różnych grupach nauk. Wartość wskaźnika w analizowanym przez Price'a zbiorze danych była znacząco wyższa dla czasopism z nauk „twardych” (fizyka: 60, biochemia: 70) aniżeli „miękkich” (nauki społeczne: ok. 42, humanistyka: ok. 10)5. Dane zgromadzone w systemie POL-index będzie można w przyszłości poddać podobnym zabiegom i sprawdzić, jak kształtują się różnice (bądź podobieństwa) między poszczególnymi grupami nauk. Takie analizy pozwolą zmodyfikować PWW, aby wskaźnik ten uwzględniał odmienne kultury cytowań.

Price (1970) zaproponowany przez siebie indeks wykorzystał także do pokazania, jaki odsetek cytowań w obrębie danego czasopisma odnosi się do tekstów, które zostały zacytowane nie później niż 5 lat, licząc od roku ich publikacji. Również w tym przypadku uwidocznił różnice między dyscyplinami, tj. wykazał, że wyższa wartość indeksu charakteryzuje nauki „twarde”, a niższa - nauki „miękkie”. Na przykład wartość indeksu w naukach społecznych dla czasopisma American Sociological Review wyniosła 35, a w naukach „twardych” dla czasopisma Journal of Nuclear Physics wyniosła 54 (Price 1970).

Wyniki uzyskane przez Price'a dla wybranych czasopism literaturoznawczych i filozoficznych zestawiliśmy z wynikami odnoszącymi się do analizowanych przez nas czasopism, tj. PL i DOJP. Wartość indeksu Price'a wynosi dla PL: 15,8. Czasopisma literaturoznawcze American Literature i Studies in English Literature analizowane przez Price'a uzyskały wyniki odpowiednio: 4 i 8. Indeks Price'a dla DOJP wynosi: 26,8. Natomiast czasopisma filozoficzne American Philosophical Quarterly i Philosophy of Science analizowane przez Price'a uzyskały wynik odpowiednio: 18 i 21 (Price 1970). Niski wskaźnik Price’a dla humanistyki jest silnym argumentem za tworzeniem odrębnego rankingu czasopism na podstawie obliczonego wskaźnika bibliometrycznego (np. PWW). Wynika to właśnie z kultury cytowań, która w humanistyce charakteryzuje się o wiele częstszym cytowaniem prac, których wiek wynosi ponad 5 lat, niż w obszarze nauk twardych.

Przedstawione wyniki odpowiadają na pytanie badawcze 3. Jaki jest rozkład cytowań ze względu na ich wiek? Jaki jest odsetek cytowań, których wiek wynosi od 1 do 5 lat (cytowania te spełniają kryteria określone we wstępnej definicji PWW)?

\subsection{Autocytowania}

Interesowały nas autocytowania, a zatem te cytowania w PL i DOJP, które odnosiły się do artykułów opublikowanych w tychże czasopismach, czyli odpowiednio cytowania PL i DOJP.

${ }^{5}$ Podobny wynik uzyskał Władysław Kolasa, na podstawie analizy cytowań zgromadzonych w Indeksie Cytowań Historiografii Mediów Polskich. Kolasa nie wskazał wartości indeksu Price’a, ale ustalił, że cytowania, których wiek wynosi od o do 3, stanowią 9,66\%, natomiast cytowania, których wiek wynosi od o do 6, stanowią 22,1\% wszystkich cytowań (Kolasa 2013). 
Odsetek autocytowań jest niski zarówno w PL (1,8), jak i w DOJP (1,2). Jednakże uzyskany wynik nie pozwala na oszacowanie poziomu autocytowań, jakie uzyskałyby PL i DOJP po analizie danych z POL-indexu (jeżeli baza objęłaby te czasopisma). Przedstawiamy odsetek autocytowań, aby zwrócić uwagę na problem wpływu autocytowań na przyszły wskaźnik PWW. Problem autocytowań został dostrzeżony i jest omawiany w naukometrii. $Z$ jednej strony autocytowania są naturalnym aspektem praktyki cytowania (McVeigh br.), z drugiej - dają możliwość manipulacji wskaźnikami bibliometrycznymi, np. wskaźnikiem Impact Factor firmy Thomson Reuters (Fassoulaki, Paraskeva, Papilas i Karabinis 2000; Seglen 1997).

Przedstawione wyniki odpowiadają na pytanie badawcze 4. Jaki jest odsetek autocytowań czasopisma?

\section{Dyskusja i uwagi końcowe}

Analiza założeń PWW z punktu widzenia humanistyki pokazała, że zaproponowana wersja tego wskaźnika bibliometrycznego nie uwzględnia specyfiki kultury cytowań w humanistyce. Wykorzystanie PWW w obecnym kształcie w ocenie krajowych czasopism naukowych może przynieść niezamierzone negatywne efekty - przede wszystkim dewaluację czasopism z nauk „miękkich” z jednoczesnym faworyzowaniem czasopism z nauk „twardych”: należy spodziewać się, że ze względu na odmienną kulturę cytowań najlepsze czasopisma z nauk „miękkich” będą miały niższą wartość PWW niż najlepsze czasopisma z nauk „twardych”. Innym niezamierzonym skutkiem może być lokalna modyfikacja wskaźnika i jego zastosowanie do ocen indywidualnego dorobku publikacyjnego.

Ograniczeniem naszych analiz jest zbiór danych, tj. cytowania z dwóch czasopism humanistycznych oraz brak symulacji wysokości wyników PWW dla różnych grup nauk na podstawie danych pochodzących z bazy POL-index. Jednakże analiza oparta na dwóch reprezentatywnych dla humanistyki czasopismach umożliwia argumentację na rzecz tezy o nieadekwatności narzędzia ewaluacyjnego, tj. PWW, do ocenianego przedmiotu, czyli do cytowalności krajowych czasopism naukowych. Drugie ograniczenie będzie możliwe do przezwyciężenia dopiero wtedy, gdy dane z bazy POL-index zostaną udostępnione do analiz.

Jeśli PWW ma być wykorzystywany w ocenie krajowych czasopism naukowych z nauk humanistycznych, to wskaźnik ten należy zmodyfikować. Trzeba podkreślić, że dla każdej grupy nauk powinno zostać przeprowadzone osobne dopasowanie wzoru PWW. Poniżej wskazujemy najważniejsze składniki pożądanej - z perspektywy naukometrycznej - modyfikacji PWW, aby wskaźnik ten mógł być użyteczny w analizach bibliometrycznych, uwzględniając specyfikę nauk humanistycznych:

- rozszerzenie zbioru danych będącego podstawą obliczania PWW o monografie i rozdziały, stanowiące główne kanały komunikacji naukowej w humanistyce. 
Ta zmiana spowoduje większe pokrycie przez bazę POL-index publikacji z zakresu nauk humanistycznych, a tym samym zwiększy wiarygodność PWW jako wskaźnika obliczanego na podstawie rozszerzonego zbioru danych;

- zwiększenie wieku cytowań we wzorze na PWW, co pozwoli na uwzględnienie specyfiki wieku cytowań, tj. dłuższego oczekiwania na pierwsze cytowania publikacji i dłuższe trwanie publikacji w obiegu naukowym w humanistyce. Zakres rozszerzenia jest możliwy do ustalenia na podstawie symulacji w oparciu o bazę POL-index;

- tworzenie odrębnych rankingów czasopism dla trzech obszarów nauki zgodnie z podziałem wykorzystywanym w „Wykazie czasopism punktowanych”. Dzięki temu porównywalne będą wartości PWW uzyskane przez czasopisma z tych samych grup nauk;

- nieuwzględnianie we wzorze na PWW autocytowań czasopisma. Ta zmiana zapobiegnie możliwym manipulacjom wskaźnikiem.

Liczenie cytowań lokalnych czasopism naukowych powinno być oparte na lokalnej bazie (Bemke-Świtilnik i Drabek, 2015). Polityka naukowa powinna zatem zakładać wspieranie i rozwijanie polskiej bazy bibliograficzno-bibliometrycznej. Tworzenie takiego narzędzia nie powinno odbywać się „przypadkowo” i opierać na dobrowolności działań redakcji czasopism, lecz winno być przemyślaną strategią obejmującą dobór źródeł, korektę wprowadzonych danych, udoskonalanie algorytmu parsowania danych, a także politykę uniemożliwiającą lub przynajmniej ograniczającą zjawisko manipulowania cytowaniami i wskaźnikami.

Doświadczenia związane z funkcjonowaniem w ewaluacji nauki wskaźnika IF pokazują, że konieczne jest monitorowanie zbioru danych stanowiącego podstawę obliczania PWW w celu identyfikacji nieetycznych praktyk czasopism, które mogą być związane z chęcią podniesienia wartości wskaźnika. Mowa tu o tzw. spółdzielniach cytowań czy o praktykach redakcji obligujących autorów do cytowania publikacji ze wskazanych czasopism. Warto mieć to na uwadze już na etapie modyfikowania i wdrażania nowej wersji PWW.

\section{Załącznik}

Dodatkowe zestawienia z ilościowych analiz PL i DOJP znajdują się w załączniku opublikowanym w serwisie figshare: Drabek Aneta, Rozkosz Ewa A., Hołowiecki Marek, Kulczycki Emanuel (2016): Raport z analizy bibliometrycznej. „Pamiętnik Literacki” i „Diametros - An Online Journal of Philosophy". figshare. https://dx.doi.org/10.6084/m9.figshare.2074285.v4.

\section{Podziękowania}

Artykuł powstał w ramach prac grupy badawczej Scientometrics. Polish Research Group (scientometrics.amu.edu.pl) realizującej projekt pt. „Współczesna polska humanistyka wobec wyzwań 
naukometrii” finansowany ze środków Narodowego Programu Rozwoju Humanistyki, nr decyzji 0057/NPHR3/H11/82/2014. Dziękujemy Monice Noworolnik-Mastalskiej za pomoc w realizacji przeglądu literatury. Za lekturę pierwszej wersji tekstu jesteśmy wdzięczni Tomaszowi Zarębskiemu.

\section{Literatura}

Barnett, G.A., Fink, E.L., Debus, M.B. (1989). A Mathematical Model of Academic Citation Age. Communication Research. 16(4): 510-531. http://dx.doi.org/10.1177/009365 089016004003.

Bemke-Świtilnik, M., Drabek, A. (2015). A citation analysis of the research reports of the Central Mining Institute: a case study: mining and environment using the Web of Science, Scopus, BazTech, and Google Scholar. Journal of Scientometric Research. 3: 15316o. http://doi.org/10.4103/2320-0057.174861.

Drabek, A. (2009). „Polska Literatura Humanistyczna Arton” - baza bibliograficzna czy indeks cytowań? W: L. Derfert-Wolf, B. Szczepańska (red.), Bibliograficzne bazy danych: kierunkirozwojuimożliwościwspótpracy. Warszawa: Stowarzyszenie Bibliotekarzy Polskich, KWE; http://www.ebib.pl/publikacje/matkonf/mat19/drabek.php [11.12.2015].

Fassoulaki, A., Paraskeva, A., Papilas, K., Karabinis, G. (2000). Self-citations in six anaesthesia journals and their significance in determining the impact factor. British Journal of Anaesthesia. 84(2): 266-269. http://doi.org/10.1093/oxfordjournals.bja.a013418.

Hammarfelt, B. (2012). Harvesting footnotes in a rural field: Citation patterns in Swedish literary studies. Journal of Documentation. 68(4): 536-558. doi.org/10.1108/002204 11211239101.

Hellqvist, B. (2009). Referencing in the Humanities and its Implications for Citation Analysis. Journal of the American Society for Information Science and Technology. 61(2): 310-318. doi.org/10.1002/asi.21256.

Jacsó, P. (2009). Five-year impact factor data in the Journal Citation Reports. Online Information Review. 33(3): 603-614. doi.org/10.1108/14684520910969989.

Kolasa, W.M. (2013). Historiografia prasy polskiej (do 1918 roku): naukometryczna analiza dyscypliny 1945-2009. Kraków: Wyd. Naukowe Uniwersytetu Pedagogicznego.

Komunikat Ministra Nauki i Szkolnictwa Wyższego z dnia 14 września 2012 r. w sprawie kryteriów i trybu oceny czasopism naukowych.

Komunikat Ministra Nauki i Szkolnictwa Wyższego z dnia 29 maja 2013 r. w sprawie kryteriów i trybu oceny czasopism naukowych.

Komunikat Ministra Nauki i Szkolnictwa Wyższego z dnia 2 czerwca 2015 r. w sprawie kryteriów i trybu oceny czasopism naukowych.

Konieczna, D. (2002). Bibliometryczna analiza publikacji cytowanych w czasopiśmie „Litteraria” w latach 1969-1999. Zagadnienia Naukoznawstwa, 1-2(151-152): 137-145.

Kulczycki, E. (2014). Zasady oceny czasopism humanistycznych i ich rola w parametryzacji jednostek naukowych. Nauka. 3: 117-140; http://www.nauka-pan.pl/index.php/nauka/ article/view/45 [11.12.2015]. 
Kulczycki, E., Rozkosz, E.A., Drabek, A. (2016). Ocena ekspercka jako trzeci wymiar ewaluacji krajowych czasopism naukowych. Nauka. 1: 107-142; http://www.nauka-pan.pl/ index.php/nauka/article/view/651 [11.12.2015].

McVeigh, M.E. (br.). Journal self-citation in the Journal Citation Reports - Science Edition (2002). W: Web of Science; http://wokinfo.com/essays/journal-self-citation-jcr/?utm_ source=false\&utm_medium=false\&utm_campaign=false [11.12.2015].

Price, D.J. de S. (1970). Citation Measures of Hard Science, Soft Science, Technology, and Nonscience. W: C.E. Nelson, D.K. Pollock (red.), Communication among scientists and engineers (3-22). Lexington, MA: Heath Lexington.

Seglen, P.O. (1997). Why the impact factor of journals should not be used for evaluating research. BMJ. 314(7079): 497-502. doi.org/10.1136/bmj.314.7079.497.

Todd, P.A., Ladle, R.J. (2008). Hidden dangers of a "citation culture". Ethics in Science and Environmental Politics. 8(1): 13-16. doi.org/10.3354/esepooo91.

Wilkin, J. (2013). Ocena parametryczna czasopism naukowych w Polsce - podstawy metodologiczne, znaczenie praktyczne, trudności realizacji i perspektywy. Nauka. 1: 45-54; http://www.nauka-pan.pl/index.php/nauka/article/view/86 [11.12.2015].

Winclawska, B.M. (1996). Polish Sociology Citation Index (principles for creation and the first results). Scientometrics. 35(3): 387-391. doi.org/10.1007/BFo2016909.

Wouters, P. (1999). The Citation Culture (doktorat, Universiteit van Amsterdam); http:// hdl.handle.net/11245/1.163066 [11.12.2015].

\section{Polish Impact Factor and Citation Cultures in the Humanities}

ABSTRACT. The article discusses the formula for a new Polish bibliometric indicator, i.e., the Polish Impact Factor (Polski Współczynnik Wpływu) from the point of view of the humanities. Our study examines two prestigious Polish humanities journals (Pamiętnik Literacki and Diametros - An Online Journal of Philosophy) to evaluate the underlying assumptions of the Polish Impact Factor. We have analyzed all articles published from 2004 to $2014(N=850, N=555$, respectively $)$ and all references included in these articles $(N=21,805, N=8,298$, respectively). When interpreting the findings, we have assumed that different groups of sciences are characterized by different citation cultures. Our findings show that the formula for the Polish Impact Factor does not take into account the most cited sources in the humanities, i.e., books and chapters. Moreover, many citations will not be included in the formula because of the citation age: the formula for the Polish Impact Factor is provided for the citations whose age is not higher than 5 years. We have analyzed the citation age of all citations and used Price's Index to interpret the result. We have found out that most of citations are older than 5 years $(84,2 \%$ and $73,2 \%$, respectively). Our analysis shows that the Polish Impact Factor is not an adequate tool for a bibliometric evaluation of the journals in the humanities in Poland. The article concludes with a discussion of how the Polish Impact Factor could be improved.

KEYWORDS: Polish Impact Factor, citation culture, humanities, bibliometrics, Polish Journal Ranking 
CYTOWANIE: Drabek, A., Rozkosz, E.A., Hołowiecki, M., Kulczycki, E. (2015). Polski Współczynnik Wpływu a kultury cytowań w humanistyce. Nauka i Szkolnictwo Wyższe. 2(46): 121-138. DOI: 10.14746/nsw.2015.2.4. 